\title{
À mesa com Olavo Bilac: impressos efêmeros como fonte e possibilidade metodológica em história cultural
}

\section{Resumo}

Em que medida uma coleção de cardápios pode revelar aspectos da rede de sociabilidades à qual pertencera um literato brasileiro, no final do século XIX? É possível trabalhar a perspectiva biográfica a partir de um conjunto de impressos efêmeros? Essas são algumas questões que este artigo pretende esclarecer. O Arquivo Histórico da Academia Brasileira de Letras guarda uma extensa coleção de cardápios reunidos por Olavo Bilac e, o estudo dos elementos presentes nesses impressos - data do banquete, local, ocasião celebrada, além dos tantos autógrafos neles contidos - permitiu recuperar, de forma original, aspectos da biografia do poeta no contexto da Belle Époque do Rio de Janeiro.

Palavras-chave: Biografia; Impressos; Olavo Bilac; Belle Époque; Rio de Janeiro.

\section{Para citar este artigo:}

GARCIA, Lúcia. À mesa com Olavo Bilac: impressos efêmeros como fonte e possibilidade metodológica em história cultural. Revista Linhas. Florianópolis, v. 16, n. 32, p. 34 - 50, set./dez. 2015. 


\title{
At the table with Olavo Bilac: ephemeral printings as resource and methodological possibility in cultural history
}

\begin{abstract}
How can a collection of menus reveal aspects of the Brazilian society where a writer took part at the end of the XIX century? Is it possible, from this ephemeral printing collection, to work with a biographical perspective? Those are some of the questions that this article intends to answer. The Arquivo Histórico da Academia Brasileira de Letras keeps an extended collection of menus gathered by Olavo Bilac and the study of the components in those printings - feast date, place, type of celebration, with all the autographs seen in some of them - allowed to retrieve, in an original way, aspects of the poet's biography during the Belle Époque context of Rio de Janeiro society.
\end{abstract}

Keywords: Biography; Printings; Olavo Bilac; Belle Époque; Rio de Janeiro. 
"A mesa é a sociedade, a união, a cordialidade..."

Olavo Bilac

Em que medida uma coleção de cardápios pode desvelar a rede de sociabilidades à qual pertencera um literato no final do século XIX? É possível trabalhar a perspectiva biográfica a partir de um conjunto de impressos efêmeros? Essas são algumas questões que este artigo pretende esclarecer.

Em sua trajetória como jornalista, poeta e conferencista, Olavo Bilac participou de inúmeros banquetes - ocasiões em que a confraternização dos convivas se dava em torno de farta e requintada gastronomia.

Por conta do seu prestígio intelectual e da sua ampla rede de sociabilidade, Bilac era nome sempre lembrado na relação dos convidados dos almoços e jantares de gala organizados por agremiações políticas, das artes ou da imprensa.

Com recepção requintada - além do variado menu, elaborado nos moldes da elegante gastronomia francesa, delicadas porcelanas, pratarias e cristais -, os banquetes oferecidos aos membros da elite intelectual e política brasileira, na transição do século XIX para o XX, celebravam desde efemérides da História pátria à conclusão de obras públicas ou de equipamentos urbanos, homenageavam um escritor, artista ou político, comemoravam seu natalício, marcavam a despedida de um intelectual que partia em viagem ou a alegria do seu regresso...

Diante do fausto dessas recepções, não é difícil relegar às motivações dos banquetes importância secundária. $O$ espírito era o de celebração regada à boa comida, com atenção aos rituais que envolviam a recepção e a etiqueta à mesa.

Os banquetes no contexto da Belle Époque do Rio de Janeiro representavam a pretensão do refinamento da elite, que preservava seu status também por meio dessas confraternizações sociais - muitas delas prestigiadas pela presença de Bilac, ora como convidado, ora como anfitrião. 
O poeta colecionara os cardápios dos tantos banquetes que participou e, a partir dos elementos impressos ou até manuscritos - data, local, ocasião a ser celebrada, autógrafos -, a pesquisa que ora se apresenta recuperou aspectos da biografia de Olavo Bilac no contexto da ambiance em que esteve inserido no Rio de Janeiro nos primórdios do século $X X$.

\section{Aproximações com a biografia do poeta}

A infância e a adolescência de Olavo Bilac (1865-1918) foram marcadas pelo rigor e austeridade da educação conservadora, seja no ambiente familiar, seja nos estabelecimentos de ensino que frequentou. Em 1908, aos 43 anos, ao visitar suas lembranças de menino, publicou em A Notícia:

[...] nunca fui verdadeiramente menino e nunca fui verdadeiramente moço [...] Fomos criados para gente macambúzia e não para gente alegre. Nunca nos deixaram gozar essas duas quadras deliciosas da vida, em que o existir é um favor divino. Os nossos avós e os nossos pais davam-nos a mesma educação que haviam recebido: cara amarrada, palmatória dura, estudo forçado, escravização prematura e estupidez das fórmulas, das regras e das hipocrisias. Tudo quanto era divertimento, estroinice, namoro, surto para o ideal e para a liberdade tinha que ser feito às escondidas. Aos dezesseis anos ainda éramos tratados como meninas [...] (PONTES, 1944, p. 22)

Quando criança, Bilac foi matriculado na escola do Padre Belmonte, à rua do Sacramento. A rotina de aulas e a severidade dos mestres tornavam o aprendizado enfadonho e, como confessou o poeta, "a voz do professor soava arrastada e monótona [...]. E, como eu, todos os outros pequenos estavam ali, sonhando, palpitando, vibrando, ansiando pela terminação do cativeiro, e namorando o ar livre, a luz, a alegria [...]" (PONTES, 1944, p. 19).

Findo o curso do Padre Belmonte, Bilac ingressou no Colégio Vitório, estabelecimento de prestígio na segunda metade do século XIX, localizado à Rua dos Latoeiros (Gonçalves Dias), 46, dirigido por Adolfo Manuel Vitório da Costa e Azevedo, 
"grande explicador de matemáticas, de osteologia e de ciências físicas e naturais" (RIOS FILHO, 2000, p. 398).

Aos 15 anos, Bilac concluiu os exames preparatórios, ambicionando formar-se em Direito para, em seguida, ingressar na carreira diplomática. Mas, seu pai, o médico Brás Martins dos Guimarães Bilac, bastante conservador, não aprovava os planos do filho. Concluindo os estudos antes da idade legal para a matrícula na Escola de Medicina, o Dr. Brás, graças ao seu prestígio, obteve uma lei de exceção, assinada pelo Imperador D. Pedro II.

Decreto $n^{\circ} 2956$ de 3 de agosto de 1880.

Autoriza o governo a mandar Olavo dos Guimarães Bilac na Faculdade de Medicina do Rio de Janeiro.

Hei de bem Sancionar e Mandar que se execute a seguinte Resolução da Assembleia Geral.

Art. $1^{\circ}$ - O Governo é autorizado a mandar admitir à matrícula do $1^{\circ}$ ano da Faculdade de Medicina do Rio de Janeiro, o estudante Olavo dos Guimarães Bilac, a quem fica dispensado o requisito da idade legal. (Fernando Jorge, 1965, p. 39)

Foi a contragosto que Bilac iniciou o curso de Medicina. Nos primeiros anos da faculdade, já demonstrava sua preferência pela Literatura, lendo com mais interesse os textos de Baudelaire e Alfred Musset do que os compêndios médicos.

A Faculdade fazia circular um jornal de nome Gazeta Acadêmica e, foi nesta folha que Bilac, aos 18 anos, publicou seu primeiro soneto "Manhã de Maio", ingressando para o Grêmio da instituição. Neste ano, em 1883, tiveram início suas rusgas com a Medicina e com a autoridade paterna, pois, no que deveria preparar lições, fazia versos para o folheto.

Com o passar dos anos e o franco afastamento do curso médico, Bilac rompeu com a figura paterna e, sem recursos imediatos, foram os amigos da Imprensa que o acolheram. Em 1887, partiu para São Paulo a fim de tornar-se Bacharel em Direito.

Republicano e abolicionista, Bilac encontrou atmosfera agradável na faculdade de Direito sendo logo admitido no jornal Diário Mercantil. Mas, o tédio não demorou a aturdir 
Bilac. Prova disso são as várias cartas endereçadas aos amigos queixando-se da garoa, do frio e da cidade de São Paulo que o aborrecia pavorosamente (PONTES, 1944, p. 102).

Retornando ao Rio de Janeiro, por força dos baixos vencimentos pagos pelos jornais, passou a colaborar nos periódicos Cidade do Rio, Novidades, Correio do Povo e no jornal a Rua (com Raul Pompeia e Paula Ney). Bilac consolidava-se como jornalista sendo já autor de versos reconhecidamente esmerados na forma.

Em 1899, atento e não menos crítico às questões políticas, Olavo Bilac ocupou o cargo de diretor do Pedagogium provando que, não obstante as lembranças tristes da infância, remanescentes da sisudez dos mestres e da palmatória do Padre Belmonte, não deixava de interessar-se pela Instrução.

Criado através do Decreto $n^{\circ} 667$, de 16 de agosto de 1890, o Pedagogium oferecia aos professores públicos e particulares cursos de formação profissional, recursos metodológicos de ponta para a época, investindo também na constituição de um Museu pedagógico e na edição da Revista Pedagógica. Foi, decerto, importante centro federal de educação que fomentou o desenvolvimento da instrução, da carreira docente e da pesquisa no cenário nacional, dentro do recém-proclamado regime republicano.

Além dos quartetos e tercetos de seus sonetos, nos jornais do início do século XX, multiplicavam-se as crônicas escritas por Olavo Bilac, denunciando seu interesse pelas questões políticas e socioculturais de seu tempo. Em 15 de outubro de 1905, durante a campanha do então vice-presidente Afonso Pena, Olavo Bilac publicou um texto na Gazeta de Notícias, detalhando a ocasião - na qual esteve presente - em que o candidato à Presidência lançou seu programa de governo, com pouca ênfase às propostas relativas à Instrução Pública.

Está sabido que o assunto magno e a plataforma política do futuro presidente. Nem a chuva contínua, nem a estreia de Sarah Bernhardt, nem as casas desmoronadas, nem as festas à oficialidade da Pátria conseguiram desviar de tal assunto a atenção e o interesse de todos.

Essa 'plataforma', lida pelo candidato no fim de um banquete suntuoso, foi o prato mais anunciado, mais esperado e mais saboreado do menu. Em vão as sopas, os polmes, os pastéis e os paparicos, os refogados de molho cheiroso e as empanadas de caça [...]; em vão! os convivas esperavam a 'plataforma', prato novo e inédito, artisticamente temperado [...] (DIMAS, 2006,v.1, p. 750) 


\section{Para além da infância e da mocidade}

Na biografia do poeta e jornalista Olavo Bilac, mereceriam maior destaque as referências à sua infância e mocidade, à cultura escolar que testemunhou e à experiência acadêmica fragmentada vivenciada precocemente, a partir dos 15 anos, quando de seu ingresso na Faculdade de Medicina.

Sua atuação como diretor do Pedagogium é igualmente digna de mais apurada investigação, sendo, portanto, um fértil terreno para pesquisas futuras.

A implementação da plataforma política de Afonso Pena, ao tornar-se Presidente, no quarto governo civil da República Brasileira, entre 1906 a 1910, com ênfase para sua ação junto à Instrução Pública e, a multiplicação dos centros de ensino técnico, poderia ser objeto para um trabalho acadêmico de maior fôlego.

Contudo, conforme cabe esclarecer, este artigo - além de evocar o Bilac poeta, jornalista, interessado nas questões nacionais e na Educação brasileira na Primeira República - tem como objetivo destacar uma coleção de impressos efêmeros cuja análise nos permite lançar várias perspectivas de estudo sobre a trajetória literária, profissional e a rede de sociabilidades a que pertencera Olavo Bilac. Desse modo, reconhecemos neste tipo de fonte documental, tantas vezes desvalorizada e descartada, uma possibilidade metodológica e de pesquisa no campo da História Cultural.

A partir do acervo de impressos investigado e que este artigo traz à luz, foi possível resgatar aspectos biográficos do poeta parnasiano, cuja riqueza e intensidade das experiências vividas merece ainda outros estudos, com lentes ampliadas, sobretudo para as imagens que compõem seu repertório iconográfico, às quais é preciso dar voz. Trata-se da coleção de cardápios reunida por Bilac que integra o acervo do Arquivo Histórico da Academia Brasileira de Letras, no Rio de Janeiro. (GARCIA, 2011)

Na mesma crônica citada anteriormente, publicada na Gazeta de Notícias de 15 de outubro de 1905, o Príncipe dos Poetas - a fim de criticar a plataforma apresentada por Afonso Pena, que pouca ênfase conferiu aos projetos para a instrução primária - teceu considerações sobre os banquetes, forma de comensalidade recorrente na Belle Époque do Rio de Janeiro - assim como em outros momentos da História da humanidade -, nos 
quais Bilac era frequentemente convidado, a exemplo da ocasião mencionada na Gazeta, que se prestou à propaganda política de Afonso Pena. Disse Bilac em sua crônica:

Não se compreende Política sem banquetes: em todos os países civilizados, é nos banquetes que os grandes homens exprimem suas ideias; teve bastante razão aquele poeta francês que escreveu: c'est en dinant qu'on gouverne les hommes...

[...] A 'plataforma' é minuciosa acerca dos problemas da política, das finanças, das indústrias, da lavoura, do comércio, da viação, da defesa em mar e em terra. Todas essas iguarias e todos esses temperos foram sabiamente misturados, em doses fartas e racionais. Mas o tempero da instrução pública?

[...] Desculpe-me Vossa Excelência, - mas é preciso, enquanto é tempo, carregar a mão neste tempero! Nós não temos no Brasil, vários problemas temerosos; temos um só, mas temerosíssimo problema: o da instrução. O problema da instrução não é um problema. É O Problema. $O$ Brasil é uma agremiação de analfabetos. E uma agremiação humana qualquer pode ter boas finanças, boa lavoura, bom comércio, boa indústria, bom exército, boa marinha; se não tiver instrução, poderá ser tudo o que quiserem, mas nunca será uma nação.

[...] Desculpe-me Vossa Excelência! Mas julgo, que de todos os temperos com que Vossa Excelência adubou o seu excelente prato, este tempero da instrução pública foi usado com uma desconsoladora parcimônia. (DIMAS, 2006, v. 1, p. 750-752)

A vida social do poeta carioca era intensa e os convites para participar de reuniões promovidas pelas agremiações da imprensa, das letras e das artes, de saraus e de banquetes proliferavam à proporção de sua popularidade.

Numa crônica espirituosa de abertura da revista Kosmos, Olavo Bilac resume a vida social concorrida da gente elegante do Rio de Janeiro no início do século XX:

Agosto e setembro são dois meses de martírio para a gente elegante e rica (ou que se supõe elegante e se finge rica) no Rio de Janeiro. As corridas e regatas, o corso, os almoços, aos jantares, o teatro, os bailes juntem tudo isso e vejam que torvelinho, que redemoinho, que maelstron. É o delírio do divertimento, é a exasperação do prazer, é o assanhamento da folia!

Uma destas manhãs, encontrei um amigo, no seu escritório, cabeceando sobre a mesa cheia de papéis. Despertei-o com um safanão:

- Dormindo aqui, a esta hora?

Ele, estremunhando, esfregou os olhos, soltou do peito um longo suspiro, e abriu a torneira das lamentações: 
- Que vida, meu amigo, que vida! Eu sou o calceta da Elegância! Em que dia estamos hoje? Sábado, não? Pois ouça a história da minha vida nesta semana fatal... No domingo tive um almoço na Tijuca, passei a tarde no Pavilhão de Botafogo a ver as regatas, e levei a família à casa do Fagundes, cuja senhora fazia anos; depois do jantar, as meninas entraram a dançar valsas; deitei-me na madrugada da segunda-feira, às 4 horas. Às 9 vim para o escritório, de onde me veio arrancar o Milcíades, para um almoço de cerimônia, que acabou às 3 da tarde; às 3 da tarde arrastaramme para um five o'clock em casa do Melo; quando cheguei à casa, já a família tinha jantado, e estava vestida para ir ao teatro; enverguei às pressas a casaca e voamos para o Coquelin. Na terça feira houve um pic nic nas Furnas, um jantar em Botafogo -, e outra vez Coquelin. Na quartafeira, caindo de sono e sobrecarregado de trabalho urgente, tive de ir a bordo de um paquete inglês receber um amigo, almocei com ele no CityClub, levei-o ao Clube dos Diários onde joguei pocker até as 4 da tarde; das 5 às $61 / 2$ fui ao Corso da Praia de Botafogo, e abalei para casa, disposto a cair na cama como uma pedra; mas as meninas queriam ir a um concerto; lá fomos; e, à saída, esbarramos com as Alcântara, que iam acabar a noite num bailarico em casa das Fonseca: e lá fui eu, cochilando, ao bailarico, para poupar lágrimas às meninas! Na quinta-feira, às 10 da manhã, quando vinha para o escritório, fui apanhado na Avenida pelo Bastos, que me forçou a ir a um almoço de caráter... íntimo onde arrasei o estômago com foie gras e champagne, e onde enchi os ouvidos de trocadilhos franceses e cançonetas. Às 4 horas, carregaram-me para uma conferência musical; às 7 tive de jantar com o Barão Procópio no Pavilhão Mourisco, e daí fui encontrar a família no Lírico. Ontem, sexta feira tive de servir de padrinho a um casamento às 11 horas; depois da cerimônia, lunch que acabou quase à noite; à noite, outra vez, Coquelin, e, depois do Coquelin, uma partida de voltarete no Guanabara. E, aqui onde você me vê, dormi apenas três horas, e tenho que estudar e despachar toda esta papelada! Que vida, meu amigo, que vida! (LIMA, 1963, V. II, pp. 602-603)

A despeito da intensa vida social de Bilac - pontuada por viagens, banquetes, festas, recepções, idas ao teatro e aos salões, salvo os excessos da crônica - é possível considerá-la quase confessional.

\section{Banquetes, cardápios e sua função social na Belle Époque do Rio de Janeiro}

Olavo Bilac, em 3 de outubro de 1907, no banquete a ele oferecido no Palace Théatre do Rio de Janeiro pela sociedade carioca, brindou os convivas com um discurso bastante representativo do significado e da função social dessas celebrações naquele tempo. Disse o poeta: 
[...] Eu estou hoje gozando aqui, minhas senhoras e meus senhores, um desses raros, exclusivos, absorventes, entontecedores instantes de alegria suprema e de suprema ventura. Ver reunida em torno de mim, nesta noite inolvidável para a minha inteligência e para o meu afeto, a representação real e legítima da mais culta sociedade do abençoado ponto da terra em que nasci, ver-vos aqui, minhas senhoras, dando luz, perfume, encanto a esta sala, honrando e nobilitando com o vosso concurso a esta festa o meu trabalho e o meu desejo de ser bom e útil; ver-vos aqui, e lembrar-me que entre os nomes dos que assinaram os convites para este banquete havia seis nomes de senhoras - seis condecorações rutilantes que até a hora da morte estrelarão o meu peito; ver aqui altas autoridades da República e da cidade, Ministros de Estado, o Senhor Prefeito do Distrito Federal, Senadores, Deputados [...] representantes da indústria, do comércio e da imprensa, e tantos amigos íntimos e queridos cuja amizade carinhosa tantas vezes tem animado e protegido a minha agitada vida de labor e de sonho [...]

Mas é força que este meu agradecimento termine por um brinde. Em nossas festas de família, quando há ainda a felicidade de estar viva, iluminando e abençoando a casa com a sua presença, a mãe sacrossanta que com o seu amor nos guiou na vida - é sempre a ela que dirigimos a última e mais carinhosa saudação. Sigamos aqui esse exemplo, e respeitemos essa tradição. Podem todos os que aqui estão acompanharme neste brinde uma vez que no Brasil não há e praza aos céus que jamais haja estrangeiros, sendo todos os que vivem nesta terra iguais, amigos e irmãos, pelo trabalho e pelo afeto. Levanto a minha taça em honra de uma grande Mãe: a Pátria Brasileira! (BILAC, 1924. pp. 71 e 81)

No discurso proferido no Palace Théatre, para além do seu sentido retórico, é possível identificar o nacionalismo do poeta e a forte carga ideológica e política das suas palavras, justificada pelo cargo que ocupava naquele ano de 1907, como secretário do então Prefeito do Distrito Federal, Francisco Marcelino de Souza Aguiar.

No rol dos banquetes presenciados pelo poeta havia também aqueles em que ele era o anfitrião, além daqueles realizados aos 16 dias do mês de dezembro de cada ano, quando os amigos rendiam-lhe homenagens por ocasião do seu natalício.

Olavo Bilac guardou estes cardápios, e guardou também tantos outros - dos almoços e jantares em que participou, desde o Império até a República, no Brasil e pelo mundo afora.

A coleção reunida por Olavo Bilac é composta por mais de duas centenas de menus. Em sua maioria impressos, outros, em menor quantidade, manuscritos, todos são 
finamente decorados, seja com desenhos assinados por artistas importantes da época, ou com ilustrações que inspiravam o prazer à mesa. Os formatos também variam; enquanto alguns cardápios de restaurante apresentam $18 \mathrm{~cm}$ de largura por 26 de altura, outros têm menor formato apresentando $9 \mathrm{~cm}$ de largura por 13 de altura.

Muitos menus que integram a coleção foram impressos no exterior, outros, no Brasil, com destaque para a Casa Leuzinger, importante oficina tipográfica do Rio de Janeiro, estabelecida na segunda metade do século XIX ou, para a Imprensa Nacional, criada em 1808 no Rio de Janeiro pelo Príncipe Regente D. João com o nome de Impressão Régia.

Compostos em sua quase totalidade na língua francesa, com exceção de alguns poucos que apresentam os pratos em língua portuguesa, os cardápios são confeccionados em papel de gramaturas distintas. No entanto, alguns se destacam pelo fino e caro material com que foram confeccionados e impressos: a seda. A coleção possui, assim, até raros exemplares em tecido.

Se do Império à República, qualquer motivo de celebração era um bom pretexto para se oferecer um banquete, a coleção guarda cardápios de jantares em homenagem a Olavo Bilac, outros celebram o IV centenário do Descobrimento do Brasil ou a visita ao Rio de Janeiro de uma famosa atriz italiana, a inauguração das obras do Porto do Rio de Janeiro ou da rede de esgoto do bairro de Copacabana.

Em francês ou em português, o que se comprova por meio dos cardápios é que, Olavo Bilac e sua rede de sociabilidade estavam acostumados a uma rotina de jantares, almoços e banquetes, cuja presença garantia a manutenção das relações sociais e do prestígio pessoal, necessários para o bom trânsito político nas instituições da elite que desejavam frequentar, manter influência ou obter privilégios.

A propósito, à época de Bilac, é bem provável que ele colecionasse menus. Afinal, cardápio constitui-se em neologismo criado em fins da década de 1890 pelo filólogo Antônio de Castro Lopes (1827-1901) para substituir a palavra menu em francês. $\mathrm{Na} 2^{\mathrm{a}}$ edição do livro Neologismos indispensáveis datada de 1909, ao tratar da palavra francesa menu, Castro Lopes afirma: 
Nobres e plebeus, ricos e pobres, sabem que nos suntuosos banquetes, ou nas casas de pasto de alta ou de medíocre categoria, chama-se afrancesadamente Menu a lista das viandas, das iguarias, enfim, o rol dos manjares.

Desculpam-se do barbarismo todos os que o empregam, por não existir em português palavra que exprima o que Menu francês significa.

Mas a verdadeira e genuína significação de Menu é miúdo, e essa palavra foi por convenção admitida para substitui esta ou outra frase semelhante: almoço, jantar ou ceia, descritos pelo miúdo, minuciosamente.

Já no artigo Focale (antigo cachez-nez) eu o disse, e ficará para sempre entendido que todas as vezes que em português não tivermos termo para exprimir alguma coisa, que em língua especial, recorramos ao grego, ou ao latim, formando um neologismo; ou com os elementos do nosso próprio idioma crêemos um novo vocabulário em condições convinháveis.

O vocábulo latino charta (papel), reunido ao vocábulo daps, dapis (comida, iguaria, manjar), pode produzir e produz, com as modificações que a eufonia requer, um termo muito mais expressivo do que o Menu francês.

Diga-se portanto Chardapio (cardapio), isto é, papel, lista das comidas, das viandas. N'esta palavra. Formada pela intima soldadura das duas latinas (Charta, e daps, dapis), estão perfeitíssimamente contidas todas as ideias, que de um modo elítico buscaram os franceses exprimir com o seu vocábulo Menu.

No intuito de mais depressa atrair a simpatia para esse neologismo, lembrarei que os franceses chamam também a essa lista Carte, cuja origem latina é charta.

"Garçon, donnez moi la carte", ouve-se a cada passo dizer tanto o francês, como o brasileiro, o português, ou qualquer outro estrangeiro.

Em conclusão; não se peça mais ao moço o Menu, nem a Carte; mas o Chardapio (cardápio), que é por todos os motivos preferível ao Menu. (LOPES, 1909, p. 31)

Artur Azevedo ao escrever O Badejo, comédia em 3 atos, em versos, representada pela primeira vez em 15 de outubro de 1898, no Teatro São Pedro de Alcântara, registrou no diálogo de seus personagens essa aversão aos estrangeirismos ao gosto de Castro Lopes:

$\begin{array}{ll}\text { Angelica } & \begin{array}{l}\text { Quer saber teu amo } \\ \text { O que arranjaste para o almoço. Fala. }\end{array} \\ \text { O Cozinheiro } & \text { Não pode ser melhor o meu cardápio. } \\ \text { Ramos } & \text { Cardápio? Não conheço essa palavra! } \\ \text { O Cozinheiro } & \begin{array}{l}\text { Foi arranjada pelo Castro Lopes } \\ \text { Eu não digo menu, que é francesismo. }\end{array} \\ \text { Ramos } & \text { Temos um cozinheiro literato! }\end{array}$




$\begin{array}{ll}\text { O Cozinheiro } & \text { Literato não sou, mas sou purista; } \\ & \text { Embirro com palavras estrangeiras. } \\ & \text { Hoje, que tudo se nacionaliza, } \\ & \text { Nacionalize-se a cozinha! } \\ \text { Ramos } & \text { Bravo! } \\ & \text { Você é um artista! } \\ \text { O Cozinheiro } & \text { Eu, um artista? } \\ \text { Ramos } & \text { Sim, um artista da culinária, } \\ & \text { E a arte não tem pátria! Porém, vamos... } \\ \text { O Cozinheiro } & \begin{array}{l}\text { Diga lá o que temos para o almoço. } \\ \text { Em primeiro lugar os acepipes. } \\ \end{array} \\ & \text { Hors-d'oeuvres não direi nem que me rachem! }\end{array}$

A extensa coleção de cardápios reunida na Academia Brasileira de Letras revela, entre outros aspectos, a rede de sociabilidade do escritor no final do século XIX e primeiro quartel do século $\mathrm{XX}$, quer pela indicação do nome do anfitrião, ou pela assinatura dos comensais, como o Prefeito Francisco Pereira Passos, o fotógrafo Marc Ferrez, os artistas Rodolpho Amoedo e Ângelo Agostini, o arquiteto Adolfo Morales de los Rios, além de escritores e intelectuais de sua época.

Bastos Tigre, amigo próximo de Bilac, em suas Reminiscências lembra que, em seu tempo, colecionar autógrafos era uma verdadeira febre no Rio de Janeiro, a exemplo do que ocorria no estrangeiro. Reinava pelo mundo afora a pandemia dos cartões postais. Era elegante colecioná-los e, ainda melhor, quando autografados por celebridades. (BASTOS TIGRE, 1992, p. 45)

Olavo Bilac não colecionava autógrafos em cartões postais. Colecionava-os em cardápios.

Analisando a coleção em conjunto - há que se registrar a presença de cardápios impressos e manuscritos -, é possível identificar que o poeta não estabeleceu um critério claro na seleção daquilo que conservou. Entre menus exuberantes confeccionados em seda, e outros cuja ilustração é assinada por artistas da importância de Julião Machado e Raul Pederneiras, há alguns pouco expressivos e que sugerem a escolha a partir de critérios subjetivos, talvez afetivos, do poeta. Entende-se daí que Bilac preservava os cardápios para revisitar os momentos vividos, em benefício da memória, como antídoto ao esquecimento. 
Nos menus estão também presentes a Confeitaria Pascoal e a Colombo, oferecendo seus tradicionais serviços nas recepções de gala em casas de particulares ou salões, entre outros estabelecimentos comerciais do início do século XX no Rio de Janeiro.

Bilac também colecionou cardápios de restaurantes que frequentou nas muitas viagens que realizou à Europa e à América Latina e guardou muitos menus dos navios em que viajou ao estrangeiro em $1^{\text {a }}$ classe.

$\mathrm{Na}$ coleção de cardápios há exemplares em nome de Domício da Gama e Guimarães Passos, sugerindo que dessas refeições Bilac talvez não tenha participado. É possível até que tivesse desfrutado do requinte daquele encontro festivo, mas, por distração, esqueceu-se de guardar o seu cardápio, tomando por empréstimo o de outros comensais para aumentar sua coleção. Há, ainda, a hipótese dessa escolha não ser ingênua e, Bilac preservar, justamente, os cardápios que pertenceram aos dois escritores por conta dos seus autógrafos. Finalmente, a possibilidade de uma doação espontânea de Domício da Gama e Guimarães Passos que, próximos ao poeta, conheciam sua predileção pelos menus.

Como se vê, as dúvidas sobre a constituição da coleção são muitas e as perguntas que sobre ela se faz também. Quando a coleção foi doada ao acervo da Academia Brasileira de Letras? Bilac, na condição de acadêmico, incorporou pouco a pouco as peças à Academia com o objetivo de preservar sua memória pessoal? Ou os cardápios teriam sido doados pela família do poeta após a sua morte? Por que há na coleção, junto aos cardápios em nome do poeta, exemplares em nome do casal "Cora e Alexandre", irmã e cunhado de Bilac? Cora também colecionava menus ou, para enriquecer a coleção do irmão, os oferecia em gesto espontâneo? Talvez pesquisas futuras respondam a essas questões.

O historiador Carlo Ginzburg nos apontou um caminho metodológico para o estudo da coleção de cardápios. Ao analisar o paradigma indiciário, modelo epistemológico surgido por volta do final do século XIX, Ginzburg defende o valor das pistas, dos indícios e dos pormenores para a explicação científica. Diz o autor que "é preciso procurar por detrás da realidade opaca, chaves de acesso privilegiadas que ajudem a decifrá-la" (Ginzburg, 2003. p. 177). 
Os cardápios de Olavo Bilac são, desse modo, chaves de acesso importantes, que permitem não somente conhecer a rede de sociabilidade do poeta, como compreender os alimentos como símbolos de pertença social.

Para além do valor estético e gráfico, os cardápios se constituem como gênero textual e podem ser entendidos como artifícios de retórica, por conta de sua terminologia ornamental, do seu objetivo enunciativo e de um padrão sociocomunicativo característico, que integra elementos históricos, sociais, institucionais e técnicos.

A dimensão menos conhecida do poeta de maior prestígio literário do Brasil na passagem do século XIX para o XX, talvez seja a do jornalista gourmet, do cronista amante da boa mesa, do poeta que se rendia às delícias e ao luxo dos banquetes e que colecionava cardápios para relembrar esses momentos de sociabilidade, comensalidade e celebração do prazer à mesa.

O estudo da coleção de cardápios de Bilac, analisada sob a perspectiva da História Cultural, mostra como documentos aparentemente inusitados - a exemplo do conjunto de menus, ou de acervos de rótulos, embalagens, folhetos e outros impressos efêmeros têm tanto a oferecer.

Vale a pena pensar essa pesquisa como um bom exemplo para aqueles que se debruçam sobre a pesquisa (auto)biográfica, uma vez que podem e devem valer-se de manuscritos ou impressos efêmeros, tais como, cadernos escolares, boletins, provas, certificados etc., para o estudo de histórias de vida através da cultura escolar. Papéis que poderiam ser descartados - como os cardápios que, para nossa sorte, Bilac reuniu em coleção - são fontes ricas em informações que merecem contextualização, embora, contraditoriamente, tantas vezes sejam ainda vistas com descrédito.

Na década de 1950, o historiador Lucien Febvre, fundador da Escola dos Annales, defendia a escolha de novos objetos de estudo no campo da História.

Com isso, a partir da segunda metade do século $X X$, muitos pesquisadores adotaram métodos e concepções diversos dos tradicionais para a realização do seu ofício, selecionando novos temas para sua prática, inserindo a História no campo intelectual da sociedade que a pensou (Pereira das Neves, 1984, p. 17-39). 
“A sensibilidade e a História: assunto novo. Não sei de livro onde seja tratado [...]”. (Febvre, 1996. P. 9).

Na segunda metade do século $X X$, ocasião que em proferiu essa frase, Lucien Febvre talvez não imaginasse que seria levado tão a sério pelos historiadores. Felizmente, desde então, até os nossos dias, a sensibilidade e a História caminham juntas.

\section{Referências}

TIGRE, Manoel Bastos. Reminiscências. A alegre roda da Colombo e algumas figuras do tempo de antigamente. Brasília: Thesauros, 1992.

BILAC, Olavo. A eloquência de sobremesa. Kosmos. Rio de Janeiro, jun.1906.

BILAC, Olavo. Chronica. Kosmos. Rio de Janeiro, 1:3, mar. 1904.

BILAC, Olavo. Últimas conferências e discursos. Rio de Janeiro: Editora Francisco Alves, 1924.

DIMAS, Antonio. Bilac: o jornalista. São Paulo: Imprensa Oficial do Estado de São Paulo, 2006. 3 volumes.

FON FON. Rio de Janeiro, ano VII, n. 9, 01/3/1913.

GARCIA, Lúcia. Para uma história da belle époque: a coleção de cardápios de Olavo Bilac. Rio de Janeiro Academia Brasileira de Letras; São Paulo: Imprensa Oficial do Estado de São Paulo, 2011.

GINZBURG, Carlo. Mitos, emblemas, sinais: morfologia e história. São Paulo: Companhia das Letras, 2003.

JORGE, Fernando. Vida e poesia de Olavo Bilac. Rio de Janeiro: Livraria Exposição do Livro, 1965. Edição do Centenário de Olavo Bilac com introdução de Menotti Del Picchia.

LIMA, Herman. História da caricatura no Brasil. Rio de Janeiro: José Olympio Editora, 1963. 4 volumes. 
LOPES, Antônio de Castro. Neologismos indispensáveis. [S. /l. S./e]. 1909.

NEVES, Guilherme Pereira das. História: A polissemia de uma palavra. Estudos Iberoamericanos. Porto Alegre, v. 10 n. 1, p. 17-39, jul.1984.

OTÁVIO, Rodrigo. Minhas memórias dos outros. Rio de Janeiro: José Olympio, 1934. 3 volumes.

PASSOS, Guimarães. Olavo Bilac. O Álbum. Rio de Janeiro, ano 1, n. 13, março de 1893. PONTES, Eloy. A vida exuberante de Olavo Bilac. Rio de Janeiro: José Olympio, 1944. 2 volumes.

RENAULT, Delso. A vida brasileira no final do século XIX: visão Sócio-cultural e política de 1890 a 1901. Rio de Janeiro: José Olympio / INL, 1987.

REVEL, Jean-François. Um banquete de palavras: uma história da sensibilidade gastronômica. São Paulo: Companhia das Letras, 1996.

RIOS FILHO, Adolfo Morales de los. O Rio de Janeiro imperial. 2. ed. Rio de Janeiro: Topbooks, 2000.

SODRÉ, Nelson Werneck. A história da imprensa no Brasil. Rio de Janeiro: Civilização Brasileira, 1966.

STRONG, Roy. Banquete: uma história ilustrada de culinária, dos costumes e da fartura à mesa. Rio de Janeiro: Jorge Zahar Editor, 2004. 